\title{
The personal factor in the maturation of epileptogenic brain scars: review and hypothesis ${ }^{1}$
}

\author{
J O H N M . P O T T E R \\ From the Department of Neurological Surgery, Radcliffe Infirmary, Oxford
}

SUMMARY Does a metabolic factor, variable but personal to the individual, determine the interval between a brain injury and the onset of late traumatic epilepsy? It could account for the unpredictability of this maturation period, and for the fact that only about $50 \%$ of brain scars give rise to epilepsy at all.

Penfield (1961) used the phrase "the silent period of strange ripening" of brain scars when discussing the unpredictable maturation period, or latent interval, between the occurrence of a cortical brain wound and the appearance of the first late seizure in a patient who is one of the unfortunate number (roughly 50\%) prone to develop this complication. Early seizures occurring in the first week or so after wounding are likely to have a different mechanism, the nature of which has been the subject of speculations by Sargent (1921) and a review by Caveness (1965). However, it will be necessary later to refer to the genetic aspects of these early fits and to their position as the heralds of late epilepsy itself.

For anyone sustaining a brain wound that does not utterly disable him, the main concern will be whether or not he is one of the fortunate $50 \%$ who will never develop seizures. The size and site of the wound will be of lesser importance, though it would be preferably not extensive nor one in the dominant hemisphere. Least of all, perhaps, would there be as much preoccupation nowadays with the gross nature of the scar as there was formerly among those brought up in the knowledge of Penfield's elegant early work (Foerster and Penfield, 1930) on the histological differences between the two main types of brain scars. There are probably few now who are convinced that differences in the proportions of glial and fibrous tissue imply much difference in epileptogenic potential; indeed, it appears never to have been more than a suggestion that this might be so. Experience since the evidence produced by Russell and Whitty (1952) has given rise to what Caveness described

'Based on a lecture given originally at the Montreal Neurological Institute on 18 September 1967

Accepted 10 October 1977 in 1965 as the "sobering thought that surgeons have not been able to reduce significantly the incidence of traumatic epilepsy since World War I"-notwithstanding the control of infection and much more careful and advanced surgical techniques. Kaplan (1961) had already expressed his own disillusionment: "it would appear therefore that the same end result of cerebro-periosteal scarring might occur regardless of whether or not the brain be covered with a graft"; and, "convulsions occurred just as frequently whether or not the [bone] defect was covered . . . with bone, plastic or metal plates. . . ."

After the scar itself, what of the purely neurophysiological factors put forward to explain the genesis of these seizures? It is now hard to believe that they, in themselves, are likely to be very important either: for example, the suggestion put forward by the late Gilbert Phillips (1954) in his concept of hyperexcitability of the recovering neurones and instability of the recovered ones. This notion fails to account for the consistently hard core of those whose recovering and recovered neurones are apparently insufficiently hyperexcitable or unstable to produce any fits at all. One would not expect perverted physical factors in themselves to operate in only one half of the population unless there was in that half some idiosyncrasy not possessed by the other. And Russell's belief (Caveness and Liss, 1961) that the loss of a piece of cortical tissue upsets a balance between inhibition and excitation cannot be accepted as the whole explanation of the epilepsy if, as often as not, epilepsy does not occur at all. None of these suggestions, therefore, accounts for the limited incidence of seizures in those with comparable wounds.

Williams (1950) suggested that, besides the in- 
heritance of a potential for epilepsy itself (the "epilepsy factor"), there is also perhaps a limiting or "anti-epileptic factor." This would presumably be an inhibitory factor the biochemical effectiveness of which was genetically determined; in fact, some inborn variation of metabolism. Alström (1950) found the hypothesis of a dominant gene and modifying polygenes the most satisfactory, and the least improbable, but this could neither be proved nor disproved. Repeatedly one finds this near $50 \%$ incidence in epileptogenic disorders: from brain tumours to infantile hemiplegia and purulent meningitis in childhood, but with an interesting exception in the Sturge-WeberKalischer disease where the rate is almost $100 \%$. Conversely, a few people seem to be exceptionally well endowed with an antiepileptic factor. According to Whitty (personal communication), in the days when "deep insulin" therapy was in use, the occasional patient did not produce the expected seizure; and it has been said that there are some who can resist even the combination of flashing lights and high doses of metrazol. And then there is the question, why are epileptics not having fits all the time? What is the nature of an antiepileptic factor which varies so much in its efficacy? Pollen and Trachtenberg (1970) have suggested that it lies in the degradation of neuroglial function during gliosis. Normal glial cells carry away enough extracellular potassium to prevent a high concentration of potassium ions building up and excessive neuronal excitability resulting. Do normal glial cells, therefore, contain the antiepileptic factor? Are some people unable to produce brain scars containing enough of it? And what is the role of, say, a known inhibitor such as gammaaminobutyric acid (GABA) in such a process?

The attractiveness of a multiple-gene factor theory of epilepsy is that it allows for the capriciousness of seizure disorders, and for the personal nature of the epilepsy of an individual sufferer. Seizures are, after all, very much a personal matter, whatever appears to be their cause; and in few other disorders do we feel more the need to treat an individual rather than a disease. For, whatever their apparent "cause", the frequency and pattern of fits, and particularly their response to anticonvulsant drugs, are a personal matter, whatever the consistency and influence of the known stimulus, its anatomical location, or the type of seizure it produces. It seems possible, too, that even Penfield's silent ripening period itself is also something belonging to the individual, and more important than any other factor. This is the hypothesis which is offered.

In studies of traumatic epilepsy, this personal, individual, constitutional, cryptogenic, or genetic factor has been relatively neglected. It need not necessarily be inherited; it could be the result of mutation. Even in dominant-gene inheritancefor example, that established for von Recklinghausen's neurofibromatosis by Crowe et al. (1956) - expression can be expected in only $50 \%$ of the offspring of affected parents; great variation is found in the degree of the abnormality shown in the phenotype; and, as in neurofibromatosis itself, there may also be an unexpectedly high mutation rate.

Perhaps it is because there appear to be so few simple genetic disorders giving rise to epilepsy that the genetic factor has been neglected. Phenylketonuria and tuberose sclerosis are probably the best known, but as Kinnier Wilson (1940) said, "to what extent latent epileptic evolution after trauma may be influenced by preexisting factors of a hereditary or personal kind is difficult to judge; the point is constantly overlooked." Caveness (1965), for example, gave this factor only 11 lines in his 430 line chapter on basic mechanisms in post-traumatic epilepsy; Russell and Whitty (1952) had insufficient data to consider it; and Jennett (1962), in the first edition of his classic monograph on epilepsy after blunt head injuries, scarcely touches on it, though in the second edition (1975) he states that he found that a positive family history was more common in patients who developed late traumatic epilepsy, but significantly so only in children. A family history was also somewhat more common in those with early epilepsy, but in this case it was more obvious in adults.

This paucity of information indicates the difficulty of investigating the genetics of epilepsy, as Metrakos and Metrakos $(1960,1961)$ have pointed out. Pratt (1967) also made the important point that the high rate of post-traumatic epilepsy tends to mask any genetical predisposition as, too, may the adult age group in many of the series studied. He further reminds us that, for epilepsy in general, the broad division into idiopathic and symptomatic, while useful as an initial step, leads to the inclusion in the latter group of patients in whom the genetical predisposition varies from small (as in post-traumatic epilepsy) to large (for example, myoclonic epilepsy). It seems clear, therefore, that the firm detection of a genetic factor for brain scar epilepsy will require sophisticated techniques. Penfield and Erickson (1941) found no evidence of an inherited tendency in their focal lesion cases, which included those due to trauma, but they admitted having made no statistical analysis. Walker (1964) found only a slightly raised occurrence in 
siblings of patients with post-traumatic epilepsy, though a definitely increased incidence in the immediate families of those with generalised convulsions. This difference may be important, but the definition of "epilepsy" must be clear. Those showing generalised seizures may have a higher predisposition than those with focal attacks and this may be mirrored in their families (as was found, for example, by Rosenbaum and Maltby (1943) in their study of eclampsia). Although there has, in general, been a failure to find a significantly high family incidence in traumatic epilepsy, the methods used are likely to have been too insensitive compared with, say, those of Jennett. Bray (1964), however, has stated firmly that the incidence of epilepsy in the families of those with severe head injuries and epilepsy is higher than in a control group, indicating "that there are both genetic and environmental factors operating in all of us." In this statement he anticipates the compromise which appears to be leading to truce talks between some sections of the embattled naturists and nurturists in other biological fields. The problem remains, however, of the proportional representation of the two factors in any given form or case of epilepsy.

An example of the complex role that inheritance may play comes from the work of Ounsted et al. (1966). Their evidence suggested that a genetic factor found in one-third of their 99 cases of temporal lobe epilepsy in children operated as follows: the children were genetically predisposed to have convulsions in response to fever over a limited period of their early life; the convulsions were expressed as status epilepticus and caused hypoxic damage to Ammon's horn, after which mesial temporal sclerosis became established and temporal lobe seizures followed later still. This suggests that one should always consider whether the genetic factor one is seeking may be a step or two removed from the process that is actually being studied.

The views of some earlier neurologists appear to have been limited by a rigid notion that epilepsy is either constitutional or symptomatic. The distinction still lingers but is now less arbitrary than in the past, since the revelations of neurosurgery, neuropathology, and neuroradiology have increased the symptomatic proportion. Doubtless the biochemists will reduce still further the constitutional part, even though some inborn tendency will remain in all varieties. An undue family or previous history of epilepsy in patients with posttraumatic seizures is regarded as evidence of this constitutional factor. Thus, in earlier times, a patient showing such evidence might have found himself regarded as suffering solely from constitutional epilepsy and denied any compensation for injury. Kinnier Wilson (1923) appeared to carry this point of view to the extreme when he said "it has been asserted almost universally that trauma may cause epilepsy; I have never been able to understand why." In this bewildering statement Wilson may simply have been implying that a head injury is merely a precipitating factor, rather than a "cause". Thus we may return to a unitary concept of epilepsy, one well expressed by Penfield and Erickson (1941): "Predisposition to epileptic seizures is partly on an hereditary basis, due to the inheritance of certain characteristics in the individual's nervous system which are most clearly evident in the electrical activity of the cerebral cortex. This inheritance is not an all or none factor, nor a unit character, but merely a greater or lesser tendency of the individual nervous system to react by excessive uncontrolled neuronal discharge to various irritative stimuli incident upon it from within or without". So, the cause of a seizure may be either an overt or a hidden brain disorder, though this division should not be overemphasised: the two may overlap. The greater the predisposition to seizures, the more subtle may be the irritative stimulus needed to provoke them; and if the cryptogenic, idiopathic, or constitutional group were to be looked upon as epilepsy which is symptomatic of the unknown, there would perhaps be a greater stimulus to seek out that which is hidden.

Early traumatic epilepsy-that variety occurring during the week or so after injury-probably has a different mechanism from that resulting later from a mature brain scar; and those with these early seizures, which may follow quite mild injuries to the head, may have a special susceptibility. Whitty (1947) found that eight out of 29 men with gunshot wounds of the brain and early seizures had a positive family history of epilepsy, suggesting that the constitutional factor was an important adjuvant cause. Moreover, 39 out of 52 convulsions were generalised, which accords with Earl Walker's (1964) finding of a significantly high incidence of a family history of seizures in those with generalised rather than focal posttraumatic fits. At the end of the second world war there were still doubts as to whether early seizures were the heralds of late ones or whether, as had been generally taught, they carried a good prognosis. Whitty, however, found that $52 \%$ of those with early fits went on to have late ones within the space of three years, and this tendency of early seizures to lead to late ones has been confirmed since by others, including Jennett (1962, 
1975) whose statistics appear conclusive about this-at least for blunt, non-missile head injuries.

It is necessary to stress here the point that if there is a genetic predisposition to early traumatic fits, as there appears to be, and if these early fits predispose to late fits, as seems certain, there must be, in the group under consideration, a genetic predisposition to late fits. Moreover, it appears from Ounsted's work that much the same thing happens in young children with purulent meningitis, where not only do early seizures also predispose to late ones, but where there is also "silent period of strange ripening" before the late ones, and where these again show the near $50 \%$ incidence.

If the development of late traumatic epilepsy is not so much a chance event, nor simply a product of the scar itself, but rather something personal to the individual, then perhaps the duration of the "silent period of strange ripening" is also something personal. And if this personal factor is really the important one, then it must be taken into account in assessing the indications for, and the results of, scar-excision operations. For example, if after a brain wound five years elapse before a man develops seizures, any follow-up study of less than five years after the scar excision will be inadequate for that particular case. And if the maturation period is as much as 10 years, as it may sometimes be, then one will have to wait 10 years before starting a valid follow-up period. The individual patient provides his own control.

To test this hypothesis, some Oxford records were examined of patients all operated on from 15 to more than 30 years previously to excise an epileptogenic scar. Unfortunately, only for 15 patients was there adequate information. The interval between wounding and the onset of epilepsy had to be known, and a follow-up obtained for at least the same amount of time after the operation in cases where seizures had recurred.

All the patients clearly had more or less localised post-traumatic scarring of the brain, but the indications for operation in the earlier cases were not as precise as they might be today. The findings are summarised in the Table. The first 10 cases fit in fairly well with the hypothesis: over a wide range of ripening periods the latent interval from wounding to fits is roughly the same as the length of the re-ripening period of the operation scar. The other five cases do not fit. Some cases merit individual mention.

CASE 1

EP was wounded at Ypres in 1917 and his penetrating left frontal brain wound was operated on,
Table Time intervals between injury and fit and operation and fit in 15 patients

\begin{tabular}{lll}
\hline Patient & Injury to fit interval & Operation to fit interval \\
\hline EP & $(9,12,21$ months $)$ & $\begin{array}{l}(1 \text { day }) \\
\text { then } 18 \text { years }\end{array}$ \\
JL & then 19 years & 12 years \\
CC & 18 years & 5 years \\
RS & 6 years & $6 \frac{1}{2}$ years \\
& $5 \frac{1}{2}$ years & 8 years \\
AS & & 5 years \\
& 4 years & 9 years \\
3 months \\
PG & & 4 years \\
CW & 4 years & 1 year \\
LA & 1 -6 years & 1 year \\
DS & 3 months & 4 months \\
LC & 3 months & 2 months \\
CC & 3 months & 2 weeks \\
HB & 1 year & 4 months \\
JH & 2 years & 2 months \\
RF & 5 years & 10 months \\
GG & 11 years & No fits in 23 years \\
\hline
\end{tabular}

31 hours after injury, by Dr Harvey Cushing. There were three major fits in the first two years, and then none at all for 19 years, during which time he took no anticonvulsant drugs. Then he had about 15 major seizures in two years. After a pneumoencephalogram had shown dilatation of the frontal horn of the left ventricle, and the EEG a focus at that site, Professor Cairns excised the scar in 1940. A major fit occurred the next day, but although an EEG focus remained, there were no further attacks until 18 years later.

\section{CASE 2}

$\mathrm{JL}$ was also a casualty in the first world war, at Passchendaele. His wound became infected, but he made a good recovery and did not develop seizures for 18 years. Then, after having his scar excised by Mr Northfield, he had no more attacks for 12 years. The patient's father had suffered from seizures, but this is the only example in the series of a positive family history of epilepsy, although the mother of another patient, PG, is said to have had an abnormal EEG record but no overt attacks.

\section{CASE 3}

AS's case is an interesting and remarkable one which illustrates the empirical effect that even nonspecific operative procedures may sometimes have on the incidence of seizures. In 1912, at the age of 26 years, she fell off her bicycle and sustained an injury in the right posterior frontal region, possibly a depressed fracture. Four years later, she started to have seizures affecting the left side of the face and developed status epilepticus. A local surgeon then carried out some form of trephining operation on the affected area which 
resulted in unconsciousness for several days and a temporary left hemiparesis, but had the effect of stopping the fits for eight years. They then recurred and a celluloid plate was fitted, after which there was a temporary worsening of the left hemiparesis, but again relief from seizures, this time for five years. When they returned, another operation was performed but, although this was merely to remove the celluloid plate, it was followed by nine years of freedom from attacks. It is disappointing to have to relate that when eventually in 1938, the scar was properly excised, the fits recurred after only three months, shortly before her death. Interestingly, the scar was found by Dr Dorothy Russell to contain a small cavernous haemangioma. This case is an example of nonspecific operative procedures (mere alterations to the scar) providing worthwhile relief from epilepsy not just once, but literally again and again.

\section{CASE 4}

CW probably had his first seizure a year after the injury, a bifrontal gunshot wound, although there was some uncertainty about this attack. However, there was a definite and major seizure six years later. The fits recurred a year after the operation, persisted regularly in spite of anticonvulsant drugs for four years, and then apparently ceased al-

\section{TIME INTERVALS}

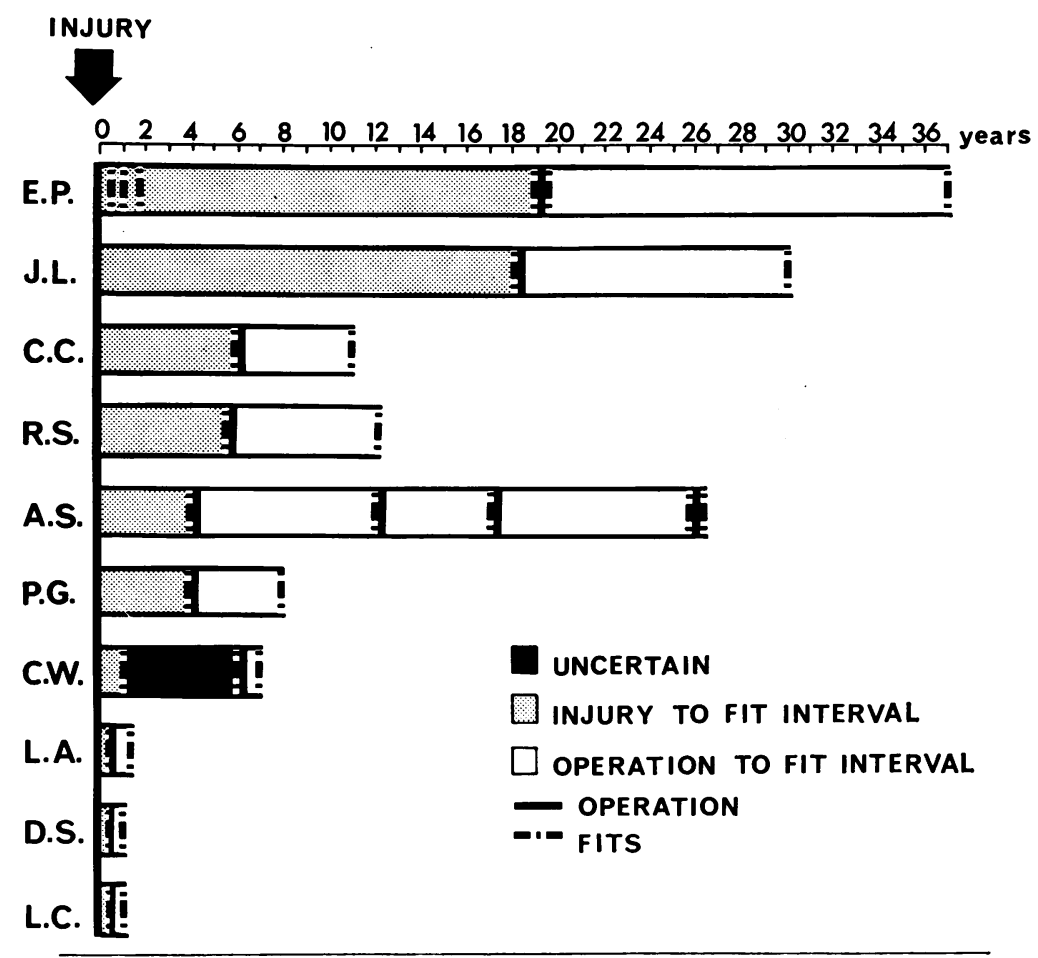

Figure Summary of time sequence of fits in 15 patients

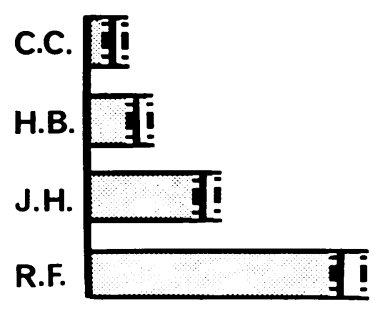

G.G. 
together at his marriage which proved to be the most effective therapy of all over the subsequent 13 years.

Only one patient in the series appears to have been relieved completely of his fits by operation. GG, when last traced, said that he had been free from fits for 23 years, and had been taking no anticonvulsant drugs for 21 years. All the other patients had developed seizures again in spite of such medication, with the exception of the first, EP, who had discontinued his drugs when he had been free of attacks postoperatively for nine years. All patients had generalised attacks at some time or other, although some also had focal elements, such as adversion or minor seizures. Only two patients (RS and PG) had had early fits within a week of the original brain wound, but these fits have not been shown in the Table. The histogram (Fig. 1) illustrates in greater detail the sequence of events in each patient.

In conclusion, it is suggested that the "silent period of strange ripening" is something personal to the individual. This hypothesis allows some reconciliation between those on the one hand who are enthusiastic about surgical treatment for brain scars associated with late traumatic epilepsy, and those on the other hand who are more sceptical, can see no rationale in replacing one scar with another, and point also to the unreliability of a procedure which, while certainly terminating seizures altogether in some patients, permits them to return sooner or later in many. In fact both points of view may be tenable, and it may be that one is, in a sense, setting a thief to catch a thief. In favourable cases, such as the first two in this series where a scar has taken 10 years or more to ripen sufficiently to produce seizures, it would seem well worthwhile to start the whole process off again if a new, surgical, scar is also going to take 10 years to ripen into an epileptogenic one. But in an individual with a short maturation period, the result of surgery may be disappointing because, if his "anti-epileptic factor" has been unable to delay the seizures once, it may be unable to do so again.

But none of this speculation sheds any real light on the true nature of the factor which we label crudely, "personal", "constitutional", "genetic", "cryptogenic"-all clichés, modern synonyms for the "humor" of Hippocrates. "Perhaps", said Penfield (1961), "no-one looking down a microscope will ever discover the secret. Perhaps the EEG provides a better approach. Perhaps neurochemistry will discover Hippocrates's 'humor'. Or perhaps it will be the physician who sees the tragic end result and tries to prevent it." If, in fact, we are dealing here with inborn errors or variations of metabolism, the key man will be, if not a neurochemist, a biochemical geneticist.

\section{References}

Alström, C. H. (1950). A Study of Epilepsy in its Clinical, Social and Genetic Aspects. Munksgaard: Copenhagen.

Bray, P. F. (1964). Discussion [on a modified concept of epilepsy]. Transactions of the American Neurological Association, 89, 142.

Caveness, W. F. (1965). In Neurological Surgery of Trauma, pp. 265-271. Office of Surgeon General: Washington.

Caveness, W. F., and Liss, H. R. (1961). Incidence of post-traumatic epilepsy. Epilepsia (Amsterdam), 2, 123-129.

Crowe, F. W., Schull, W. J., and Neel, J. V. (1956). A Clinical Pathological and Genetic Study of Multiple Neurofibromatosis. Charles C. Thomas: Springfield, Illinois.

Foerster, O., and Penfield, W. (1930). The structural basis of traumatic epilepsy and results of radical operation. Brain, 53, 99-119.

Jennett. W. B. (1962). Epilepsy after Blunt Head $\square \dot{\omega}$ Injuries. Heinemann: London.

Jennett, W. B. (1975). Epilepsy after Non-Missile Head Injuries. Heinemann: London.

Kaplan, H. A. (1961). Management of craniocerebral trauma and its relation to subsequent seizures. Epilepsia (Amsterdam), 2, 111-116.

Metrakos, J. D., and Metrakos, K. (1960). Genetics of convulsive disorders. I. Neurology (Minneapolis), $10,228-240$.

Metrakos, K., and Metrakos, J. D. (1961). Genetics of convulsive disorders, II. Neurology (Minneapolis), 11, 474-483.

Ounsted, C., Lindsay, J., and Norman, R. (1966). Biological Factors in Temporal Lobe Epilepsy. Heinemann: London.

Penfield, W. (1961). Introduction to Symposium on Post-traumatic Epilepsy. Epilepsia (Amsterdam), 2, 109-110.

Penfield, W., and Erickson, T. C. (1941). Epilepsy and Cerebral Localization. Baillière, Tindall and Cox: London.

Phillips, G. (1954). Traumatic epilepsy after closed head injury. Journal of Neurology, Neurosurgery, and Psychiatry, 17, 1-10.

Pollen, D. A., and Trachtenberg. M. C. (1970). Neuroglia: gliosis and focal epilepsy. Science, 167, 1252-1253.

Pratt, R. T. C. (1967). The Genetics of Neurological Disorders. Oxford University Press: London.

Rosenbaum, M., and Maltby, G. L. (1943). Cerebral dysrhythmia in relation to eclampsia. Archives of Neurology and Psychiatry (Chicago), 49, 204-213.

Russell, W. R., and Whitty, C. W. M. (1952). Studies in traumatic epilepsy. I. Journal of Neurology, Neurosurgery, and Psychiatry, 15, 93-98. 
Sargent, P. (1921). Some observations on epilepsy. Brain, 44, 312-328.

Walker, A. E. (1964). Discussion of a modified concept of idiopathic epilepsy. Transactions of the American Neurological Association, 89, 141.

Whitty, C. W. M. (1947). Early traumatic epilepsy. Brain, 70, 416-439.

Williams, D. (1950). New orientations in epilepsy.
British Medical Journal, 1, 685-692.

Wilson, S. A. K. (1923). The role of trauma in the aetiology of organic and functional nervous disease. Journal of Neurology and Psychopathology, 4, 133147.

Wilson, S. A. K. (1940). Neurology, p. 1525. Edward Arnold: London. 